\title{
Acoustic to Electric Pitch Comparisons in Cochlear Implant Subjects with Residual Hearing
}

\author{
Colette Boëx, Lionel Baud, Grégoire Cosendai, Alain Sigrist, Maria-Izabel Kós, \\ and Marco Pelizzone \\ Centre Romand d'Implants Cochléaires, Department of Otolaryngology-Head and Neck Surgery, Cantonal University Hospital \\ of Geneva, Geneva, Switzerland
}

Received: 17 August 2005; Accepted: 15 December 2005; Online publication: 1 February 2006

\begin{abstract}
The aim of this study was to assess the frequencyposition function resulting from electric stimulation of electrodes in cochlear implant subjects with significant residual hearing in their nonimplanted ear. Six cochlear implant users compared the pitch of the auditory sensation produced by stimulation of an intracochlear electrode to the pitch of acoustic pure tones presented to their contralateral nonimplanted ear. Subjects were implanted with different Clarion ${ }^{\circledR}$ electrode arrays, designed to lie close to the inner wall of the cochlea. High-resolution radiographs were used to determine the electrode positions in the cochlea. Four out of six subjects presented electrode insertions deeper than $450^{\circ}$. We used a two-interval (one acoustic, one electric), two-alternative forced choice protocol (2I-2AFC), asking the subject to indicate which stimulus sounded the highest in pitch. Pure tones were used as acoustic stimuli. Electric stimuli consisted of trains of biphasic pulses presented at relatively high rates [higher than 700 pulses per second (pps)]. First, all electric stimuli were balanced in loudness across electrodes. Second, acoustic pure tones, chosen to approximate roughly the pitch sensation produced by each electrode, were balanced in loudness to electric stimuli. When electrode insertion lengths were used to describe
\end{abstract}

Correspondence to: Marco Pelizzone - Centre Romand d'Implants Cochléaires • Hôpitaux Universitaires de Genève • Rue Micheli-duCrest, 24, CH-1211 Genève 14, Switzerland. Telephone: (22) 3728246; fax: (22) 372-8287; email: Marco.Pelizzone@hcuge.ch electrode positions, the pitch sensations produced by electric stimulation were found to be more than two octaves lower than predicted by Greenwood's frequency-position function. When insertion angles were used to describe electrode positions, the pitch sensations were found about one octave lower than the frequency-position function of a normal ear. The difference found between both descriptions is because of the fact that these electrode arrays were designed to lie close to the modiolus. As a consequence, the site of excitation produced at the level of the organ of Corti corresponds to a longer length than the electrode insertion length, which is used in Greenwood's function. Although exact measurements of the round window position as well as the length of the cochlea could explain the remaining one octave difference found when insertion angles were used, physiological phenomena (e.g., stimulation of the spiral ganglion cells) could also create this difference. From these data, analysis filters could be determined in sound coding strategies to match the pitch percepts elicited by electrode stimulation. This step might be of main importance for music perception and for the fitting of bilateral cochlear implants.

Keywords: cochlear implant, electrode insertion, pitch

\section{INTRODUCTION}

The main principle used to transmit pitch information with multichannel cochlear implants is to stimulate different intracochlear electrodes distribut- 
ed along the scala tympani. This principle exploits the discovery of von Békésy (1960): the place along the normal cochlea of maximal basilar membrane oscillation varies according to the frequency of acoustic tones. This observation was characterized mathematically by the frequency-position function of Greenwood (1961, 1990). For cochlear implants, the function describing the pitch evoked by electric stimulation versus the place of electrodes along the cochlea is not known yet.

Pitch sensations produced by multichannel cochlear implants have been extensively investigated in bilaterally deaf subjects using pitch-ranking experiments (Simmons et al. 1979; Shannon 1983; Townshend et al. 1987; Dorman et al. 1990; Busby et al. 1994; Nelson et al. 1995; Collins et al. 1997; Collins and Throckmorton, 2000) or pitch-estimation experiments (Eddington 1980; Tong et al. 1983; Tong and Clark 1985; Shannon 1993; Busby et al. 1994; Cohen et al. 1996a; Busby and Clark 1997; Collins et al. 1997). These studies demonstrated that electric stimulation of the ear produced complex auditory sensations, one component of which was similar to pitch. The pitch sensation generally depended on both the electrode position inside the cochlea and the rate of the electric stimulus. Electric stimulation of apical electrodes tended to produce low pitch sensations, whereas stimulation of basal electrodes produced high pitch sensations. However, the lack of an acoustic reference (bilaterally deaf subjects) imposed some limitations on the pitch-ranking or pitch-estimation results just mentioned above.

These limitations can be overcome using pitchcomparison experiments with cochlear implant subjects who present significant residual hearing in their nonimplanted ear. Bilger (1977) conducted pitchcomparison experiments with one such subject. This subject received one bipolar electrode pair in the scala tympani. The experiment consisted in adjusting the electric pulse rate to match the pitch sensations produced by acoustic sine waves of various frequencies ranging from 63 to $500 \mathrm{~Hz}$. Results showed that perceived pitch increased with electric pulse rate, with exact equivalence to acoustic frequency up to about $160 \mathrm{~Hz}$. Then the pitch from electric stimulation saturated. The influence of electrode position on pitch could not be assessed with this subject because only a single electrode pair was implanted. Eddington et al. (1978a,b) reported acoustic to electric pitch-comparison experiments with one unilaterally deaf subject. Two types of pitch-comparison experiments were conducted: (1) during surgery under local anesthesia, the pitch elicited by one electrode stimulated in monopolar mode at $200 \mathrm{pps}$ and placed successively at 19 and $25 \mathrm{~mm}$ inside the cochlea matched acoustic tones of 2000 and $1500 \mathrm{~Hz}$, respectively; (2) after surgery, the subject had trouble performing direct pitch comparisons because auditory sensations produced by the same electric signal sounded somewhat "fuzzy." Another method of determining pitch was used. It consisted in estimating pitch differences on a scale from -3 to +3 . In this second experiment, the equivalent pitches were 1560 and $1225 \mathrm{~Hz}$, for electrodes positioned at about 16 and $20 \mathrm{~mm}$ inside the cochlea, respectively. These data were roughly consistent with pitch estimates on the basis of Greenwood's frequency-position function for acoustic tones. Dorman et al. (1994) reported acoustic to electric pitch-comparison experiments with one subject implanted with the Ineraid electrode array. The subject had relatively significant residual hearing in his nonimplanted ear up to 500 $\mathrm{Hz}$, but no response to higher frequencies. On his most apical electrode (inserted about $22 \mathrm{~mm}$ from the round window), the subject matched electric sine waves of $125,200,300$, and $400 \mathrm{~Hz}$ to acoustic sine waves of $135,228,347$, and $390 \mathrm{~Hz}$, respectively. These data suggested that low-frequency sine-wave stimulation could be used to transmit voice pitch via the Ineraid cochlear implant. Surprisingly, however, when the same procedure was repeated on more basal electrodes, pitch matches increased in frequency by only about $57 \mathrm{~Hz}$ each time the location of the electric stimulation moved more basal by $4 \mathrm{~mm}$, much less than predicted by Greenwood's frequencyposition function for acoustic tones. Blamey et al. (1996) conducted pitch-comparison experiments with 13 subjects implanted with the Cochlear ${ }^{\mathrm{TM}} 22$ electrode array. In this group, subjects had relatively poor residual hearing in their nonimplanted ear (group averages were $85 \mathrm{~dB}, \mathrm{SD} \mathrm{14}$, at $250 \mathrm{~Hz} ; 98 \mathrm{~dB}$, SD 12, at $500 \mathrm{~Hz} ; 105 \mathrm{~dB}, \mathrm{SD} 11$, at $1000 \mathrm{~Hz} ; 105 \mathrm{~dB}$, SD 13, at $2000 \mathrm{~Hz}$; and $109 \mathrm{~dB}, \mathrm{SD} \mathrm{15}$, at $4000 \mathrm{~Hz}$ ). They matched acoustic pure tones to electric stimuli of 100,250 , or 800 pps presented on different electrodes. Both electrode position and electric pulse rate influenced pitch comparisons. Results were quite variable across subjects. One major conclusion from this work was that the pitch elicited by stimulation of intracochlear electrodes is generally lower than estimated by Greenwood's frequency-position function. Among possible explanations for this observation, they suggested that electric stimulation of intracochlear electrodes could directly excite ganglion cells in the modiolus rather than their peripheral ends in the cochlea. Taken together, these results suggest that Greenwood's frequency-position function for the normal human cochlea cannot be used to accurately predict the pitch sensation produced by the electric stimulation of an intracochlear electrode.

In this study, we asked to six patients, implanted in our center with Clarion ${ }^{\circledR}$ (Advanced Bionics Corpo- 
ration, Sylmar, CA, USA) cochlear implant systems, to compare the pitch of the auditory sensation produced by stimulation of their intracochlear electrodes (one at a time) to the pitch of acoustic pure tones presented to their nonimplanted ear. Each patient presented significant residual hearing in the nonimplanted ear, and some of them presented relatively deep electrode insertions. According to the lateral position of the electrode in the cochlea (e.g., close to the outer or to the inner wall), the same insertion length can correspond to different insertion angles (Kós et al. 2005). Hence, in this study, we also measured electrode insertion angles, expressed in degrees $\left({ }^{\circ}\right)$, to describe the function relating insertion angles to frequency of acoustic tones at pitch match.

\section{METHODS}

Subjects

All six subjects volunteered to participate in the experiments conducted according to the recommended ethical guidelines of the Declaration of Helsinki. As described in Table 1, all subjects were adults who had been using their implant for at least 6 months at the time of the study. Subject Cp18 received the SSeries ${ }^{\mathrm{TM}}$ electrode array with the electrode positioning system (EPS; Fayad et al. 2000), which is an independent silicone part designed to place the electrode array close to the modiolus. Subjects Fp36 and Fp39 received the HiFocus ${ }^{\mathrm{TM}}$-II electrode array also with the EPS, which, in this case, is attached to the array. Subjects H70, H58, and $\mathrm{H} 68$ received the HiRes $^{\mathrm{TM}} 90 \mathrm{~K}$ electrode array, which carries no EPS. Except for subjects Cp18 and H68, they were all good performers with their implant, as indicated by average consonant identification scores (Pelizzone et al. 1993, six tests gathered within two sessions, Table 1).

The hearing thresholds of the nonimplanted ear of each patient are described in Figure 1. Subject
$\mathrm{H} 70$ presented hearing thresholds better than $45 \mathrm{~dB}$ HL up to $4000 \mathrm{~Hz}$. Subjects Cp18, H58, Fp36, and Fp39 presented hearing thresholds better than $65 \mathrm{~dB}$ HL at frequencies lower than 500, 1000, 2000, and $3000 \mathrm{~Hz}$, respectively. Subject H68 presented hearing thresholds better than $55 \mathrm{~dB}$ HL for frequencies higher than $500 \mathrm{~Hz}$. Hearing thresholds higher than $80 \mathrm{~dB}$ are not indicated. Subject H70 presented the best hearing thresholds. While his left ear turned deaf suddenly (unknown etiology, Table 1), his right ear has been turning deaf progressively (unknown etiology). Subject Cp18 did not present either the same etiology of deafness for both ears (unknown and sudden for the implanted ear and unknown progressive for the nonimplanted ear).

\section{Electrode design}

The S-Series ${ }^{\mathrm{TM}}$ electrode array consists of eight radial pairs of electrodes numbered from 1 to 8 from the most apical to the most basal pair (Kessler 1999). Each electrode pair has one medial and one lateral contact. Electrode contacts are $0.3-\mathrm{mm}$ diameter balls. The distance separating adjacent pairs of electrodes is $2 \mathrm{~mm}$. The total length of this electrode array is $25 \mathrm{~mm}$ from the "reference neck" to the most apical electrode.

The HiFocus ${ }^{\mathrm{TM}}$-II and HiRes ${ }^{\mathrm{TM}} 90 \mathrm{~K}$ electrode arrays consist of 16 electrodes numbered from 1 to 16 from the most apical to the most basal pair. In addition, both arrays present two nonactive references at their base. Electrodes have a rectangular shape of $0.4 \times 0.5$ $\mathrm{mm}$. For the HiFocus ${ }^{\mathrm{TM}}$-II electrode array, the distance separating adjacent electrodes is $0.9 \mathrm{~mm}$, and the distance between the first nonactive reference mark and the most basal electrode is $2.5 \mathrm{~mm}$. The distance between both nonactive references is also $3 \mathrm{~mm}$. For the HiRes ${ }^{\mathrm{TM}} 90 \mathrm{~K}$ electrode array, the distance separating adjacent electrodes is $0.85 \mathrm{~mm}$, and the distance between the first nonactive reference mark and the most basal electrode is $3 \mathrm{~mm}$. The distance between both nonactive references is also $3 \mathrm{~mm}$.

\section{TABLE 1}

Subjects' year of birth, year of cochlear implant surgery, side of implant, type of electrode array, medial consonant identification performance, and etiology of deafness of both ears

\begin{tabular}{|c|c|c|c|c|c|c|c|}
\hline \multirow[b]{2}{*}{ Subject } & \multirow{2}{*}{$\begin{array}{l}\text { Year of } \\
\text { birth }\end{array}$} & \multirow{2}{*}{$\begin{array}{l}\text { Year of } \\
\mathrm{Cl} \text { surgery }\end{array}$} & \multirow{2}{*}{$\begin{array}{l}\text { Side of } \\
\text { implant }\end{array}$} & \multirow[b]{2}{*}{ Electrode array } & \multirow{2}{*}{$\begin{array}{c}\text { Consonant } \\
\text { identification \% (SD) }\end{array}$} & \multicolumn{2}{|c|}{ Etiology } \\
\hline & & & & & & Ipsi-Cl & Contro- $\mathrm{Cl}$ \\
\hline $\mathrm{H} 70$ & 1947 & 2004 & Left & HiRes $^{\mathrm{TM}} 90 \mathrm{~K}$ & $73(5)$ & Unknown Sudden & Unknown progressive \\
\hline Cp18 & 1949 & 1999 & Left & S-Series ${ }^{\mathrm{TM}} \mathrm{EPS}$ & $49(3)$ & Unknown + trauma & Ménière's disease \\
\hline Fp36 & 1951 & 2001 & Right & HiFocus $^{\mathrm{TM}}$-II EPS & $84(7)$ & Neurosarcoïdosis & Neurosarcoïdosis \\
\hline Fp39 & 1945 & 2001 & Right & HiFocus $^{\mathrm{TM}}$-II EPS & $74(7)$ & Ménière's disease & Ménière's disease \\
\hline H58 & 1930 & 2004 & Left & HiRes ${ }^{\mathrm{TM}} 90 \mathrm{~K}$ & $67(9)$ & Unknown progressive & Unknown progressive \\
\hline H68 & 1949 & 2004 & Left & $\mathrm{HiRes}^{\mathrm{TM}} 90 \mathrm{~K}$ & $55(4)$ & Ménière's disease & Ménière's disease \\
\hline
\end{tabular}



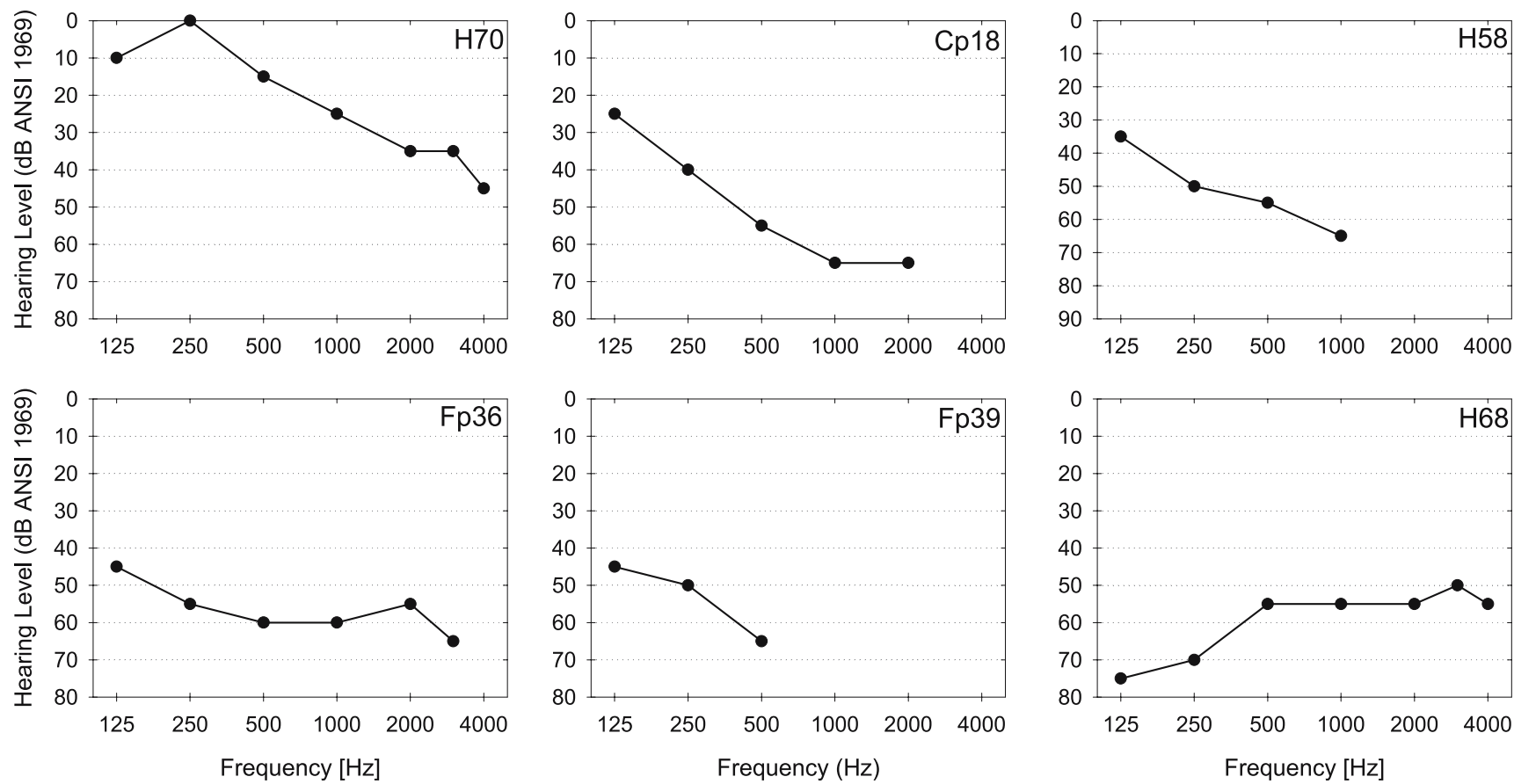

FIG. 1. Hearing thresholds (pure tones) of the nonimplanted ear of each subject.

\section{Postoperative radiographs}

Postoperative radiographs were collected to determine the exact positions of the intracochlear electrodes. These radiographs were made according to the modified Stenver's view described by Marsh et al. (1993): the X-ray beam was aimed at the infraorbitomeatal line, the midsagittal plane of the skull making an angle of about $50^{\circ}$ with the film plane. An exposure of about $80 \mathrm{~mA} \mathrm{~s}$ and $80 \mathrm{kV}$ was used (fluoroscopy, Philips Integris). The round window was estimated according to the method described by Cohen et al. (1996b) and Xu et al. (2000). The insertion angle of electrodes belonging to the first turn of the spiral made by the electrode array were computed from the center of this first turn, using as reference the $0^{\circ}$ reference line (Figure 2). In cases of subjects H70, Cp18, and H68 who presented deep electrode insertions, the insertion angle of electrodes belonging to the second turn of the spiral made by the electrode array were computed from the center of this second turn, using as reference the $720^{\circ}$ line.

Determination of electrode insertion length was straightforward on the basis of the position of the round window and of the mechanical design specifications of each electrode array.

\section{Stimuli}

Pitch comparisons were obtained between acoustic stimuli presented to the nonimplanted ear and electric stimuli presented to the implanted ear on one individual electrode. Acoustic stimuli were 0.3 -s bursts (30-ms rise-decay times) of sine waves. These acoustic stimuli were generated by a sound card, amplified and played over headphones to the nonimplanted ear.

Electric stimuli were 0.3 -s bursts (0-ms rise-decay times) presented on one single electrode in monopolar mode: the stimuli were applied between one electrode (a medial contact in case of the S-Series ${ }^{\mathrm{TM}}$ array) and the base of the implanted receiver-stimulator case used as a far-field ground. They consisted of negative firstphase, biphasic pulses similar to the stimulation used daily with their Clarion ${ }^{\circledR}$ processor (Cp18: $76.9 \mu \mathrm{s}$ / phase, 833 pps; H70, Fp36, Fp39, and H68: $21.6 \mu$ s/ phase, 1447 pps; H58: $43.2 \mu \mathrm{s} /$ phase, 723 pps). The electric stimuli were generated using the Clarion ${ }^{\circledR}$ Research Interface-I (CRI-I) for patient Cp18 and the Clarion ${ }^{\circledR}$ Research Interface-II (CRI-II) for all other patients. We controlled the CRI-I as described in Boëx et al. (2003). To control the CRI-II, we adapted the custom signal processing I/O software provided by Victor Noel (Cochlear Implant Research Laboratory, Massachusetts Eye and Ear Infirmary and Massachusetts Institute of Technology) to work with our own Matlab ${ }^{\mathrm{TM}}$ interface.

\section{Loudness balancing protocols}

Electric loudness balancing protocol. First, the electric stimuli were balanced for loudness across electrodes. 

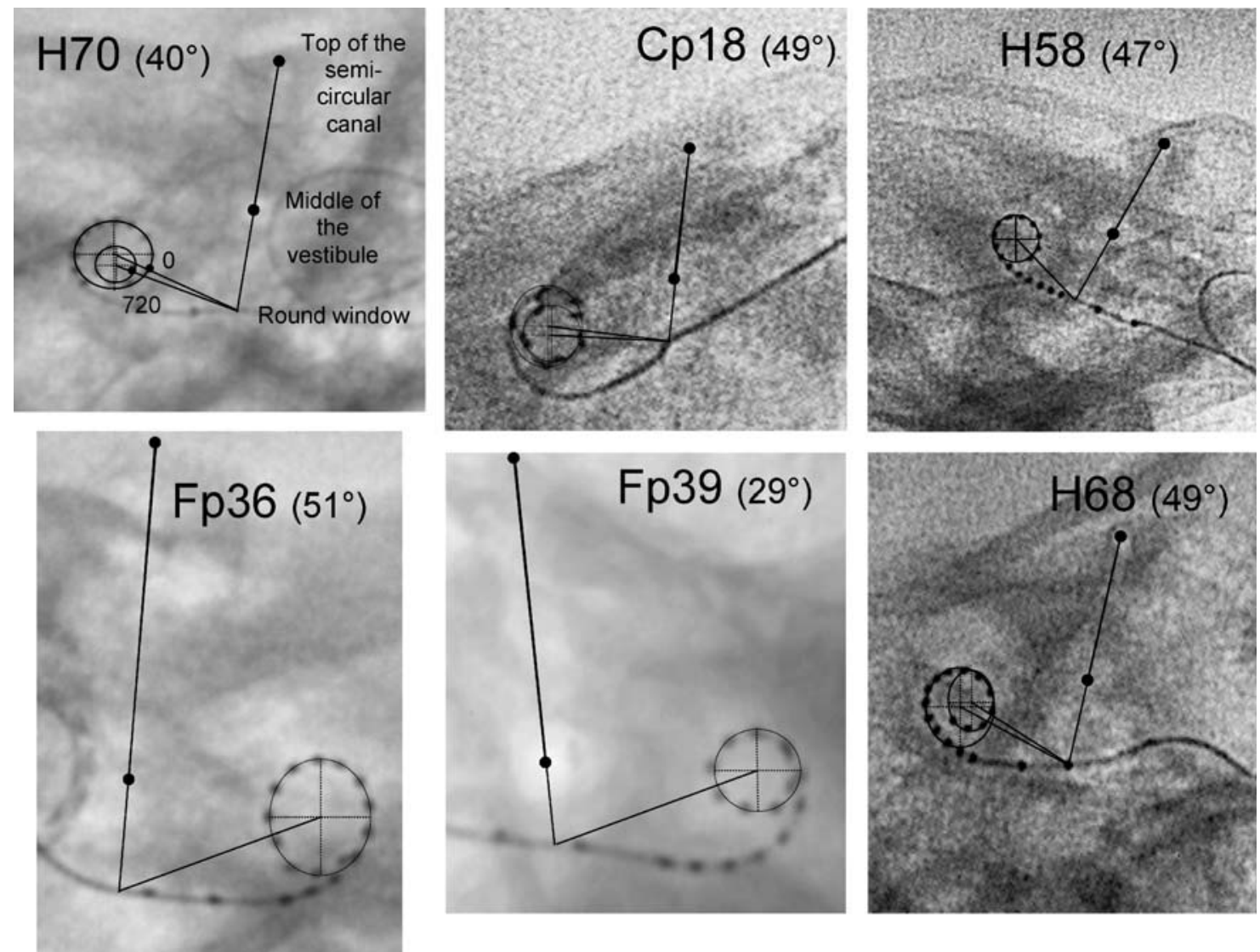

FIG. 2. Radiographs obtained for each subject following the modified Stenver's view. The angle of the midsagittal plane of the skull made with the film plane at the time of the radiograph is indicated in parentheses. The line going through the top of the superior semicircular canal and the center of the vestibule crosses the electrode array at the estimated site of the round window. The

Initially, a loudness reference was defined as the amplitude of the stimulus producing a comfortable loudness sensation on one electrode placed in the middle of the array. We used 2I-2AFC for loudness balancing across electrodes. We presented to subjects test pairs (method of constant stimuli) consisting of the stimulation of the reference electrode (one burst, constant amplitude) and of the stimulation of the reference's neighboring electrode (one burst, varying amplitude). Eight amplitudes of stimulation of the neighboring electrode were computed to encompass the loudness sensation equivalent to that produced by the reference-electrode stimulation (from clearly softer to clearly louder than the reference; resulting to about 80 and $120 \%$ of the balanced amplitude; step of about $5 \%$ of the balanced amplitude). Stimuli were presented in a random order, either reference electrode first or neighboring electrode first. The subject was asked to indicate which interval contained the loudest sensation. If the subject could not perceive a difference in loudness, he was in- line going through the estimated site of the round window to the center of the first turn of the spiral made by the electrode array is used as the $0^{\circ}$ reference line. In cases of deep electrode insertions, the line going through the estimated site of the round window to the center of the second turn of the spiral made by the electrode array is determined as the $720^{\circ}$ line.

structed to guess. Feedback was not provided. Bursts were separated by an interval of $0.5 \mathrm{~s}$. Each amplitude was tested five times in a random order. The whole 40 presentations were analyzed computing the average responses at each amplitude and fitting a psychometric function to those data. The psychometric function (i.e., the cumulative integral of a Gaussian distribution) was of the form $f(x)=1 / 1+$ $\mathrm{e}^{1.6 / \sigma\left(\mu_{-}\right)}$( $\mu$ and $\sigma$ corresponding to the mean and standard deviation of the underlying Gaussian distribution, respectively). The $50 \%$ point of the best fit to this function was used to determine the most equivalent loudness balanced amplitude. The 25 and $75 \%$ points were used to define error bars (they described the spread of the psychometric curve). Once we obtained the amplitude producing a loudness balanced sensation on one electrode, that electrode was then used as a reference to balance its own neighboring electrode. Hence, we balanced, for instance, pairs $8-9,8-7,9-10,7-6$, etc. until all available electrodes were tested. 
Electric to acoustic loudness balancing protocol. We used the same psychophysical method to balance the loudness of the acoustic stimuli to the loudness sensation produced by electric stimulation of each electrode, each electrode being stimulated at the stimulus level determined by the previous "electric loudness balancing protocol." The frequency of the acoustic tones used for each electrode was chosen to approximate roughly the pitch sensation produced by the electrode stimulation (one single frequency for each electrode determined preliminary by initial pitch comparisons controlled by the experimenter). We presented to subjects test pairs made of the stimulation of the electric stimulus (one burst, constant amplitude) and of the acoustic tone (one burst, varying amplitudes). Eight acoustic levels were computed to encompass the loudness sensation equivalent to that produced by the electrode stimulation (from clearly softer to clearly louder than the electrode, resulting to a range of about 10 $\mathrm{dB}$ SPL, steps of about $1.25 \mathrm{~dB})$. Stimuli were presented in a random order, either electrode stimulus first or acoustic tone first. Each amplitude was tested five times in a random order. The whole 40 presentations were analyzed in the same way as discussed previously.

\section{Pitch-comparison protocol}

Loudness balanced stimuli were then used for the pitch-comparison measurements. We used again the same 2I-2AFC protocol. We presented to subjects test pairs made of the stimulation of one electrode (one burst, fixed electrode, previously balanced stimulus) and of one acoustic tone (one burst, different frequencies, fixed acoustic level determined previously). Both stimuli were presented in a random order, either electrode stimulus first or acoustic tone first. Ten acoustic tones, logarithmically spaced in frequency, were computed to encompass the pitch sensation equivalent to that produced by the electrode stimulation (from clearly lower to clearly higher than the reference, resulting to a range of about one octave). The subject was asked to indicate which interval contained the highest pitch. Ten different presentation lists of these 10 frequencies were generated according to a balanced Latin square design to control randomization of the 10 frequencies within the 10 presentation lists. One pitch comparison measurement was completed when the 10 different lists (i.e., 100 pairs) had been presented. Data analysis was conducted computing the average responses at each frequency and fitting a psychometric function to those data. The $50 \%$ point of the best fit to this function was used to determine the most equivalent acoustic frequency. The 25 and $75 \%$ points were used to define error bars.

\section{RESULTS}

\section{Intracochlear electrode positions}

Figure 2 presents the radiographs obtained for each subject. Subject Cp18 presented the deepest insertion $\left(675^{\circ}\right)$. Subject $H 58$ presented the shallowest insertion $\left(365^{\circ}\right)$. Subject Fp39 presented an unusual coiling of the electrode array, suggesting an atypical orientation of the cochlea. Her superior semicircular canal could be visualized when the midsagittal plane of her skull made an angle of about $29^{\circ}$ with the film plane, whereas it can usually be seen with an angle of about $50^{\circ}$ in other subjects.

Figure 3 indicates the insertion angle versus the insertion length, both measured from radiographs, for each electrode. For comparison, the positions of the inner and outer walls of the cochlea, as well as the organ of Corti, are drawn on the same graph as given in the $3 \mathrm{D}$ reconstruction work of Kawano et al. (1996). The electrode arrays lie close to the inner wall (Fp39 and H58) or between the organ of Corti and the inner wall. This was to be expected because these electrode arrays (the S-Series ${ }^{\text {TM }}+$ EPS, the HiFocus $^{\mathrm{TM}}$-II + EPS, as well as the HiRes ${ }^{\mathrm{TM}} 90 \mathrm{~K}$ electrode arrays) were all designed to lie close to the inner wall.

\section{Pitch comparisons}

Before conducting pitch comparisons, the electric stimuli were balanced for loudness across the different electrodes. Then, the frequency of the acoustic stimulus approximating roughly the pitch sensation produced by electrode stimulation was determined, and the loudness of the acoustic stimuli was balanced to the loudness sensation produced by electric stimulation of each electrode. These data were collected for each subject following the procedures described in Methods and are summarized in Appendix.

As an example of one pitch comparison measurement, in Figure 4, we present the data collected on electrode 7 for subject Cp18. During the acoustic to electric loudness balancing measurements, an acoustic tone at a frequency of about $820 \mathrm{~Hz}$ approximately matched the pitch perception elicited by electric stimulation of this electrode. Accordingly, a series of 10 acoustic stimuli, logarithmically spaced over the frequency range from 410 to $1640 \mathrm{~Hz}$, was used to obtain the pitch-comparison data. The best fit of the psychometric function determined the equivalent acoustic frequency at $791 \mathrm{~Hz}$ (50\% point). 

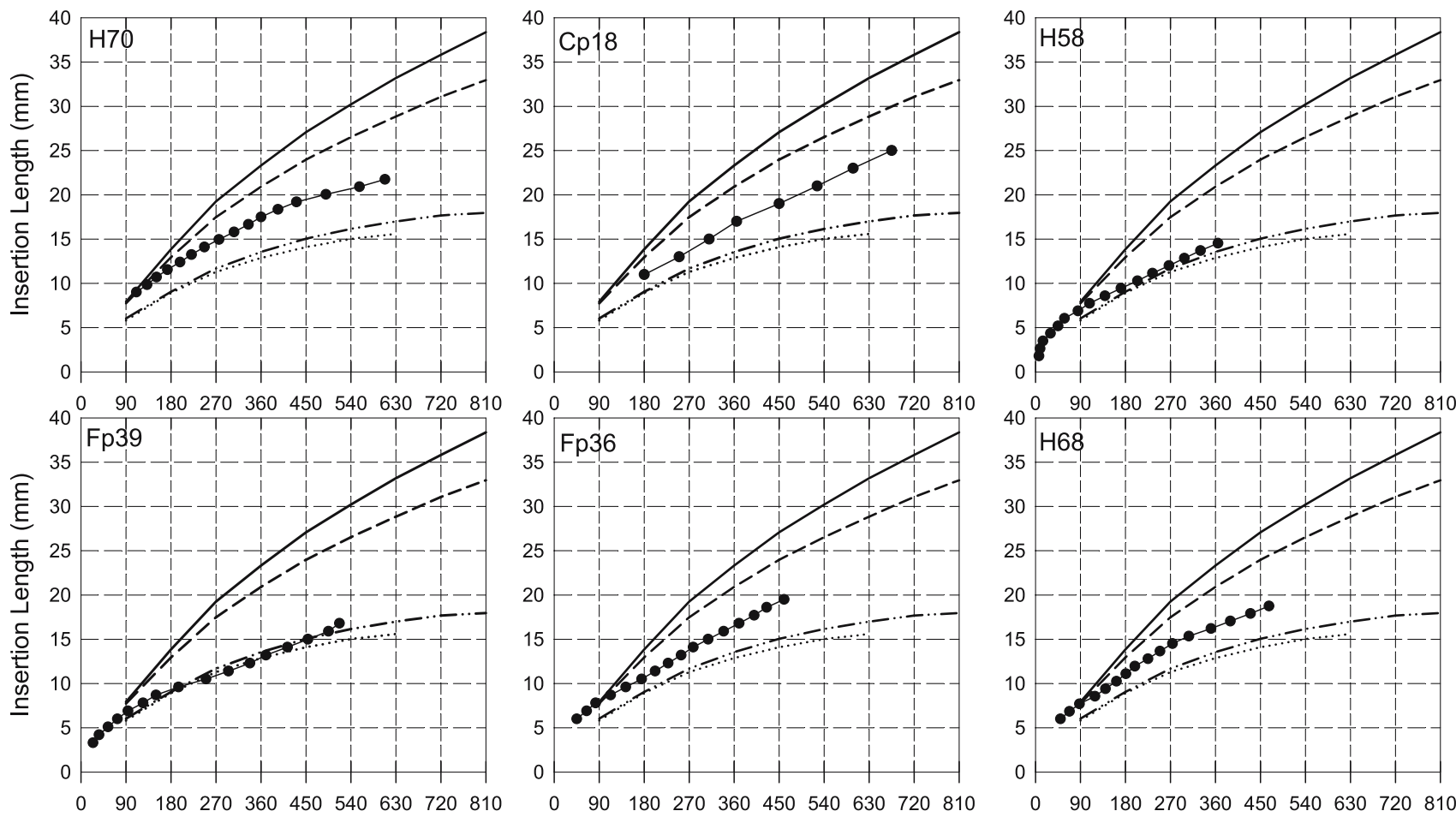

\begin{tabular}{llllllllll}
\hline 0 & 90 & 180 & 270 & 360 & 450 & 540 & 630 & 720 & 810
\end{tabular}

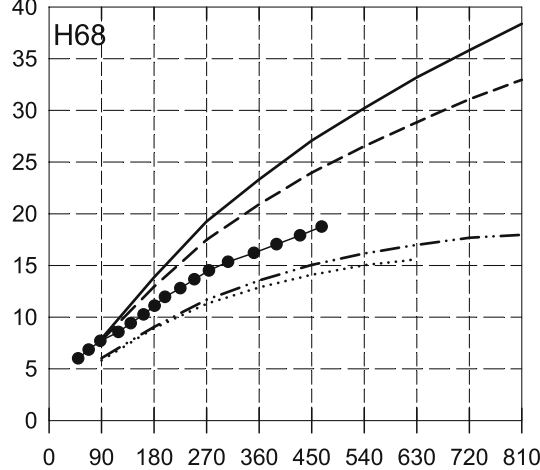

Insertion Angle $\left(d^{\circ}\right)$

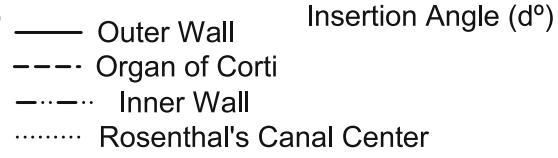

Insertion Angle $\left(d^{\circ}\right)$

(Kawano et al., 1996)

FIG. 3. Estimation of electrode positions (insertion lengths and angles) for each subject in comparison to the positions of the outer (solid line) and inner (second dashed line) walls of the cochlea, as well as the organ of Corti (first dashed line) and the spiral ganglion (dotted line), as described in the reconstruction work of Kawano et al. (1996).

The same procedure was repeated to collect pitch comparison data on several electrodes for each subject. Figure 5 presents the equivalent acoustic frequencies obtained by pitch comparison for each electrode versus their insertion length $(\mathrm{mm})$ from the round window, for all six subjects. The frequency of acoustic stimuli at match generally increased progressively when electric stimuli were applied successively from the most apical (electrode 1) to the most basal electrode. Greenwood's (1990) func-

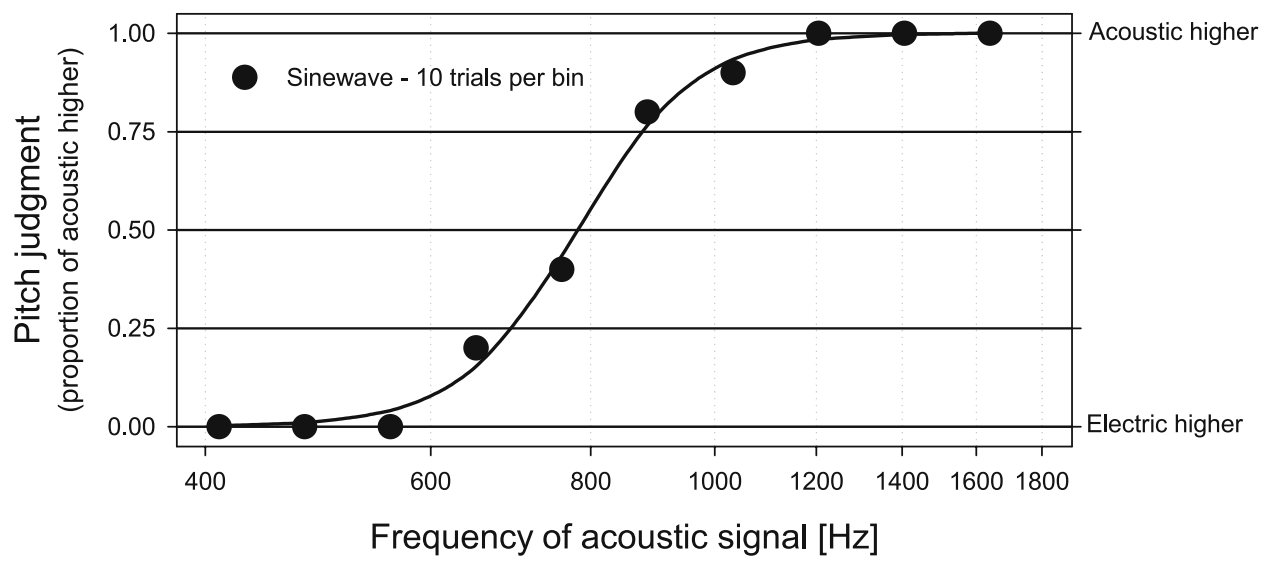

FIG. 4. Pitch-comparison data for electrode 7 in subject Cp18. The proportions of pitch judgments in which the acoustic stimulus were judged higher in pitch are plotted as a function of the frequency of the acoustic stimuli. 

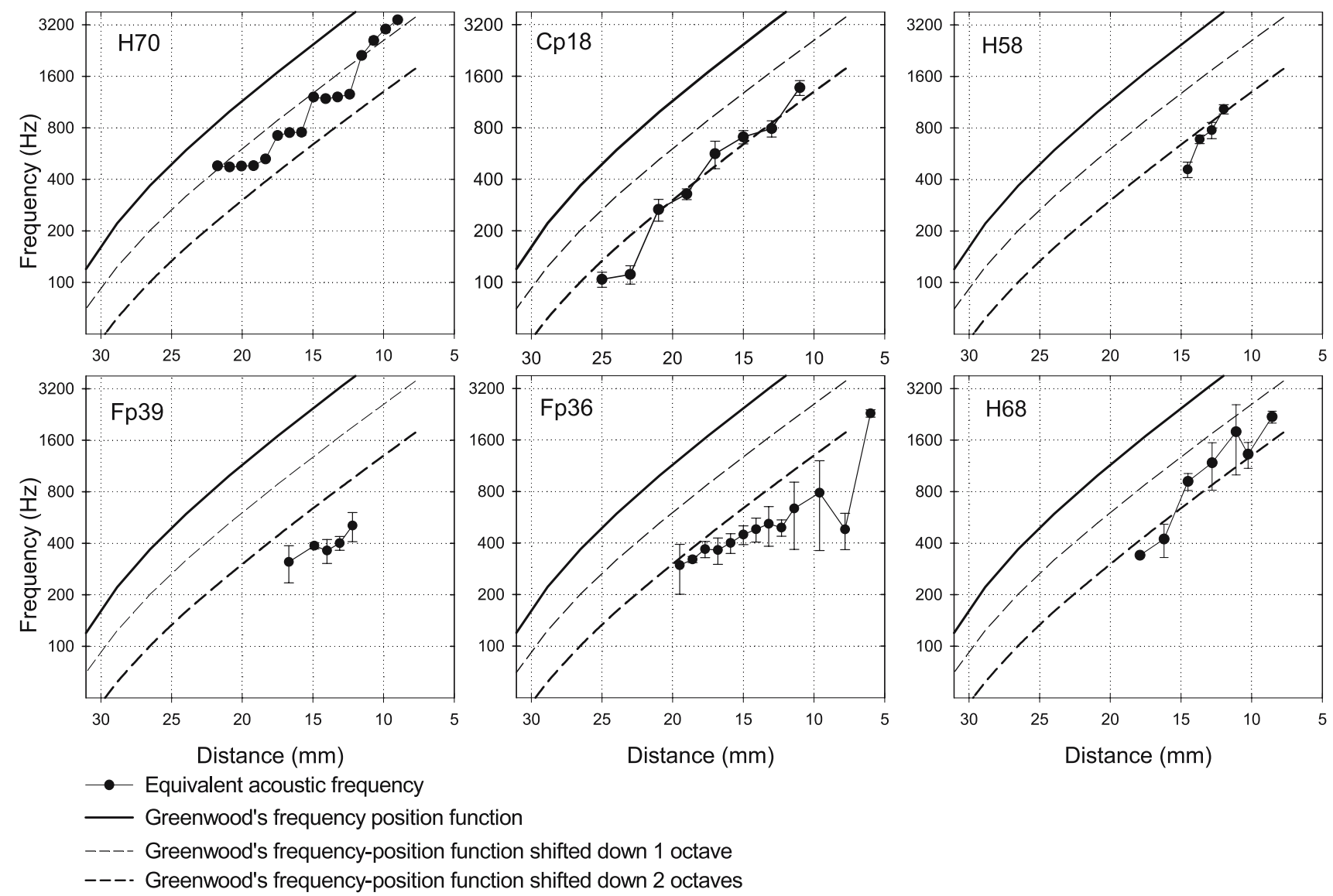

FIG. 5. Equivalent acoustic frequency versus electrode insertion length $(\mathrm{mm})$, for all six subjects. The solid lines represent Greenwood's (1990) frequency-position function for a normal ear, using proportion of basilar length ( $a=0.06 ; k=1$; total length: $35 \mathrm{~mm}$ ). Both dashed lines represent the same function shifted down by one or two octaves.

tion for a normal ear is also plotted for comparison. In all cases, the frequencies of acoustic stimuli at match were much lower than Greenwood's frequency-position function. Data obtained for all six subjects fell close to Greenwood's frequency-position function shifted down by one octave (H70), two octaves (Cp18, H58, H68), or even below (Fp39, Fp36). These results can be partly explained by the fact that Greenwood's function indicates the frequency of acoustic tones, expressed in hertz, versus the place of maximal basilar membrane oscillation along the organ of Corti, expressed in millimeters from the round window, whereas the present Clarion ${ }^{\circledR}$ electrode arrays are designed to lie close to the inner whole (Figure 3). In consequence, the length of the electrode array should not be used in Greenwood's function. For example (see Figure 3 and Appendix), electrode 6 of subject Fp36 and electrode 3 of subject Fp39 are both inserted at $15 \mathrm{~mm}( \pm 0.1 \mathrm{~mm})$, but measured insertion angles are $308^{\circ}$ and $454^{\circ}$, corresponding to about 19 and $24 \mathrm{~mm}$ of the organ of Corti, respectively. Hence, insertion angles can vary over a range of, for example, $146^{\circ}$, for the same insertion length and for the same type of electrode array (HiFocus ${ }^{\mathrm{TM}}$-II + EPS). Obviously, these two electrodes stimulate different regions of the cochlea because their lateral positions are markedly different. It is hence more relevant to use insertion angles to plot pitch comparison data in cochlear implant subjects.

Figure 6 presents the equivalent acoustic frequencies obtained for each electrode versus their measured insertion angle $\left(^{\circ}\right)$ for all six subjects. To express the frequency-position function of a normal ear versus angles, we used the reconstruction work of Kawano et al. (1996, Table 2), where they listed angles $\left(^{\circ}\right)$ versus percentage lengths of the organ of Corti. We also drew the frequency-position function that could result from the excitation of the spiral ganglion cells (hairline), using the function modeling the projection of fibers from the organ of Corti to the spiral ganglion as described by Sridhar et al. (2005) and using again the reconstruction work of Kawano et al. to assign angles to percentages of the 

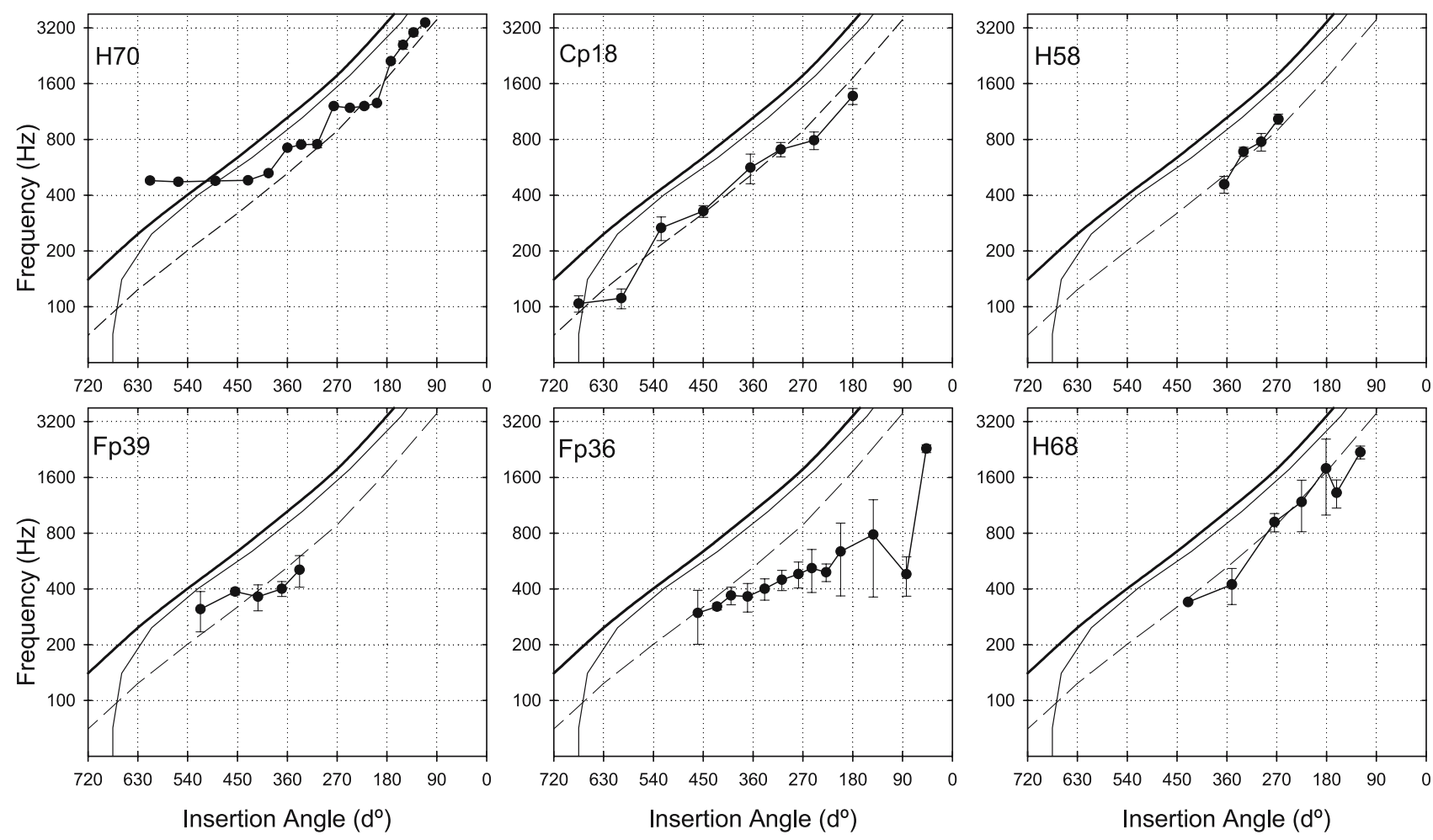

- Equivalent acoustic frequency

- Frequency position function adapted for angles

---- Frequency-position function adapted for angles, shifted down 1 octave

Frequency-position function estimated for the spiral ganglion cells

FIG. 6. Equivalent acoustic frequency versus electrode insertion angle for all six subjects. The solid lines represent the frequency-position function of a normal ear, adapted for angles. The dashed line represents the same function shifted down by one octave. The curved line represents the frequency-position function estimated for the stimulation of the spiral ganglion cells (see text for details).

length of the spiral ganglion. The frequencies of acoustic stimuli at match were again lower than estimated by the frequency position function of a normal ear. Data obtained for subjects Cp18, H58, and H68 appeared close to the frequency-position function of a normal ear shifted down by one octave. Data obtained for subject H70 also appeared close to the frequency-position function of a normal ear shifted down by one octave, whereas plateaus can be observed. These plateaus could be explained by the presence of dead regions, such as those observed in postmortem studies of temporal bones from implanted subjects. Data obtained for subject Fp39 were situated between the frequency-position function and its shift down by one octave. Nevertheless, the unusual coiling seen on the radiograph might induce errors in the determination of the position of the most apical electrodes. Data obtained for subject Fp36 were progressively lower, from apical to basal electrodes, than what predicted by the frequencyposition function shifted down by one octave. Similar pitch comparison data to those collected for subject
Fp36 were observed also by Blamey et al. (1996). Cohen et al. (1996a) also observed irregular low pitch estimations and proposed to explain them by the possible presence of local cochlear structures that would allow current flow to more apical regions.

\section{DISCUSSION}

Pitch sensations produced by electric stimulation of an intracochlear electrode depend on both the electrode position inside the cochlea and the rate of the electric stimulus. Increasing the rate of stimulation from 100 pps up to about 600 pps produces increasingly higher pitch sensations, and this effect tends to asymptote at higher rates (Simmons et al. 1979; Eddington 1980; Tong et al. 1983; Townshend et al. 1987; Busby and Clark 1997). In this study, stimulation rates were always higher than 700 pps and were held constant during the experiments. Thus, the shifts in pitch observed in the present work show an effect of electrode position. 
Our data are consistent with previous observations of several authors (see Introduction) in showing that electric stimulation of apical electrodes tended to produce low pitch sensations, whereas stimulation of basal electrodes produced increasingly higher pitch sensations. However, when the frequencies of sine waves producing an equivalent pitch are plotted versus measurements of electrode positions expressed by insertion length from the round window, these data fall systematically two octaves or more below Greenwood's frequency-position function for a normal ear. Part of this marked discrepancy is because of the fact that electrode insertion length is not the most adequate measure, especially if electrode arrays lie close to the inner wall of the cochlea. For example, according to the data of Kawano et al., a one-turn insertion corresponds to $21 \mathrm{~mm}$ along the organ of Corti and to only $13 \mathrm{~mm}$ along the inner wall of the cochlea. If an electrode is placed close to the organ of Corti, the discrepancy found between pitch comparisons data reported for insertion length or insertion angles will be minimal (e.g., subject H70, basal electrode, high pitch). If an electrode is placed close to the inner wall, the discrepancy will be major (e.g., subject Fp39). Insertion angles should be used to describe electrode insertion and to estimate the place of excitation. Using angle measurements reduced the discrepancy, but data fell still about one octave below Greenwood's function.

Previously, relatively few acoustic to electric pitchcomparison data have been collected with such high stimulation rates. Only Blamey et al. (1996) reported measurements on eight subjects using 800-pps stimuli and plotted their data versus insertion angles. In spite of the large variability observed across listeners, most of their data collected at such rates clearly indicated pitch sensations that were also lower than would be predicted by the frequency-position function of a normal ear for acoustic tones. Therefore, our data extend Blamey et al.'s data to deeper insertions, to lower frequencies, to subjects presenting better residual hearing. Our data are also consistent with the work by James et al. (2001) who conducted "contralateral masking experiments in cochlear implant users with residual hearing in the non-implanted ear." They observed maximum masking of the sensation produced by electric stimulation when the center frequency of narrowband acoustic noise was lower than expected from the position of the stimulating electrode. Taken together, these data demonstrate that pitch sensations produced by intracochlear electric stimulation are lower than would be predicted by Greenwood's frequency-position function for a normal cochlea.

First, a possible explanation is the variability of the numbers of turns of the cochlea across subjects. Note that we could not determine either the length or the number of turns of individual cochleas from radiographs. One octave shift is obtained for an angle shift of about $90^{\circ}$, according to the angular frequencyposition function of a normal ear (Figure 6). The standard deviation of the average number of turns of the organ of Corti was about 0.11 turn (about $40^{\circ}$ ) in Kawano et al. Hence, the variability in the numbers of turns of the cochlea across subjects is certainly too small to explain fully the one-octave shift we observed.

Second, from radiographs, we can only estimate the position of the round window. We plan to realize multislice computed tomography (Verbist et al. 2005) to measure exactly the position of the round window. If a difference was found between the estimated position and the real position of the round window, this difference could partly explain the one-octave shift we observed. In addition, multislice tomography will allow to measure each electrode position more precisely than what is possible from radiographs.

Third, hearing in impaired ears is different from hearing in normal ears and might bias pitch-comparison data. All subjects had moderately impaired hearing at low frequencies and no measurable thresholds at high frequencies (above $3000 \mathrm{~Hz}$, except H68). In case of outer hair cell damage, the point of maximum sensitivity of the tuning curves can shift up to one octave to lower frequencies (Liberman et al. 1986), which should result in a perception of higher pitch than normal. Hence, this effect cannot explain our observation. Psychophysical tuning curves (PTC) measurements conducted previously with subject Cp18 demonstrated that functional auditory nerve fibers were present at low frequencies and had the required frequency selectivity to allow pitch judgments without bias. The other subjects were not available for additional PTC measurements. We plan to conduct the same acoustic to electric pitch comparisons in one subject with normal hearing in his nonimplanted ear. These measurements will determine the potential importance of the bias introduced by comparisons using impaired ears. As James et al. described, another source of deviation from the frequency-position function of a normal ear is that this function was obtained for low acoustic levels, whereas the present measurements were realized at levels ranging from 65 to $90 \mathrm{~dB}$ SPL. The point of maximum basilar membrane oscillation moves toward higher frequencies with increasing acoustic levels (Sellick et al. 1982; Zwislocki and Nguyen 1999). Hence, this point cannot explain the fact that we found lower pitch elicited by electric stimulation than by acoustic tones.

Fourth, another explanation might account for systematic shifts in pitch-comparison data in cochlear 
implant subjects. Electrodes implanted in the cochlea might not activate auditory nerve fibers according to the tonotopic organization of the organ of Corti. The site of neural excitation may be situated more centrally. Postmortem studies of temporal bones from implanted subjects have shown surprisingly poor peripheral axon survival (Johnson et al. 1982; Galey 1984; Clark et al. 1988; Terr et al. 1989; Linthicum et al. 1991; Fayad et al. 1991; O’Leary et al. 1991; Zappia et al. 1991; Marsh et al. 1992; Nadol et al. 1994; Kawano et al. 1998; Nadol et al. 2001). Thus, intracochlear electrodes may directly stimulate spiral ganglion cell bodies in Rosenthal's canal. Kawano et al., realizing 2D and 3D reconstructions of the cochlea, showed that Rosenthal's canal was about 1.875 turns, much shorter than the organ of Corti (2.625 turns). The frequency-position function that could result from the excitation of the spiral ganglion cells (hairline in Figure 6) indicates that if an electrode directly stimulates spiral ganglion cells, it should produce a lower pitch than if it stimulates peripheral axons, particularly for frequencies lower than about $400 \mathrm{~Hz}$. However, the excitation of auditory fibers at the level of spiral ganglion cells would not explain fully the one-octave shift we observed. Along the same lines, Frijns et al. (2001), on the basis of an electroanatomical model of the excitation produced by intracochlear electrodes in humans, showed that possible "cross-turn" effect could lead to the stimulation of lower frequency fibers: electrodes close to the inner wall of the cochlea could stimulate spiral ganglion cells or axons originating from more apical locations of the cochlea, leading to lower pitch sensations. This phenomenon cannot be excluded as a partial explanation of our observations.

\section{CONCLUSIONS}

We measured the frequency-position function resulting from electric stimulation of the cochlea with Clarion ${ }^{\circledR}$ cochlear implant users, presenting residual hearing in their nonimplanted ear. We found lower pitch matches, by about one octave, than predicted by the frequency-position function of a normal cochlea. At present, we cannot explain fully this observation.

These experimental data may be helpful in the design analysis filters of sound coding strategies devoted to restore natural perception of pitch. This process could be of main importance in the perspective of improving music perception or performances of bilateral cochlear implant users.

\section{ACKNOWLEDGMENTS}

This research work was supported by the Swiss National Research Foundation (FNRS grants no. 32-56352.99 and 3168263.02). We thank all members of the "Centre Romand d'Implants Cochléaires" for their help in the laboratory. We thank C. Knuchel and M. Munster for their help in gathering the radiographs. We thank V. Noel and D. K. Eddington for providing us the CRI-II custom signal processing I/O software. Most of all, we are especially grateful to the subjects for the time and the effort they devoted to this study.

\section{APPENDIX: DETAILED STIMULI FOR EACH SUBJECT}

This summarizes for each subject the electrode insertion lengths and angles and the details of stimuli used to realize

Subject H70, HiRes ${ }^{\mathrm{TM}} 90 \mathrm{~K}$ no EPS, $22 \mu \mathrm{s} /$ phase, 1447 pps

\begin{tabular}{|c|c|c|c|c|c|}
\hline \multirow[b]{2}{*}{ Electrode } & \multicolumn{2}{|c|}{ Insertion } & \multirow[b]{2}{*}{ Electric stimuli (C.U.) } & \multicolumn{2}{|c|}{ Acoustic stimuli } \\
\hline & Length (mm) & Angle $\left(^{\circ}\right)$ & & Frequency $(\mathrm{Hz})$ & Level (dB SPL) \\
\hline 1 & 21.75 & 608 & $487(4)$ & 460 & $63(3.5)$ \\
\hline 2 & 20.9 & 557 & 478 (28) & 500 & 59 (3.9) \\
\hline 3 & 20.05 & 490 & $485(47)$ & 440 & $63(0.8)$ \\
\hline 4 & 19.2 & 431 & $500(0)$ & 440 & $68(2.9)$ \\
\hline 5 & 18.35 & 394 & $520(11)$ & 530 & $61(4.9)$ \\
\hline 6 & 17.5 & 360 & $535(20)$ & 720 & $59(2.3)$ \\
\hline 7 & 16.65 & 335 & $542(32)$ & 770 & $64(3.3)$ \\
\hline 8 & 15.8 & 306 & 550 (Ref.) & 730 & $64(0.4)$ \\
\hline 9 & 14.95 & 276 & $558(42)$ & 1200 & $65(3.3)$ \\
\hline 10 & 14.1 & 247 & $572(14)$ & 1040 & $68(1.8)$ \\
\hline 11 & 13.25 & 221 & $558(29)$ & 1080 & $66(5.1)$ \\
\hline 12 & 12.4 & 198 & $578(4)$ & 1100 & $66(0.1)$ \\
\hline 13 & 11.55 & 173 & $563(20)$ & 1400 & $71(2.8)$ \\
\hline 14 & 10.7 & 151 & $520(9)$ & 2500 & $66(2.4)$ \\
\hline 15 & 9.85 & 132 & $469(1)$ & 2900 & $62(1.4)$ \\
\hline 16 & 9 & 111 & $408(4)$ & 3050 & $63(7.5)$ \\
\hline
\end{tabular}




\begin{tabular}{|c|c|c|c|c|c|}
\hline \multicolumn{6}{|c|}{ Subject Cp18, S-Series $^{\mathrm{TM}}+$ EPS, $77 \mu \mathrm{s} /$ phase, 833 pps } \\
\hline \multirow[b]{2}{*}{ Electrode (medial) } & \multicolumn{2}{|c|}{ Insertion } & \multirow[b]{2}{*}{ Electric stimuli (C.U.) } & \multicolumn{2}{|c|}{ Acoustic stimuli } \\
\hline & Length (mm) & Angle $\left(^{\circ}\right)$ & & Frequency $(\mathrm{Hz})$ & Level (dB SPL) \\
\hline 1 & 25 & 675 & 75 & 100 & 88 \\
\hline 2 & 23 & 598 & 85 & 110 & 81 \\
\hline 3 & 21 & 526 & 95 & 260 & 78 \\
\hline 4 & 19 & 450 & 105 & 330 & 82 \\
\hline 5 & 17 & 365 & 105 & 550 & 83 \\
\hline 6 & 15 & 310 & 110 & 700 & 87 \\
\hline 7 & 13 & 250 & 125 & 820 & 90 \\
\hline 8 & 11 & 180 & 65 & 1290 & 80 \\
\hline
\end{tabular}

Subject Fp36, HiFocus ${ }^{\mathrm{TM}}$-II + EPS, $22 \mu \mathrm{s} /$ phase, 1447 pps

\begin{tabular}{|c|c|c|c|c|c|}
\hline \multirow[b]{2}{*}{ Electrode } & \multicolumn{2}{|c|}{ Insertion } & \multirow[b]{2}{*}{ Electric stimuli (C.U.) } & \multicolumn{2}{|c|}{ Acoustic stimuli } \\
\hline & Length (mm) & Angle $\left(^{\circ}\right)$ & & Frequency $(\mathrm{Hz})$ & Level (dB SPL) \\
\hline 1 & 19.5 & 460 & $259(42)$ & 290 & $80(0.3)$ \\
\hline 2 & 18.6 & 425 & $271(42)$ & 300 & $81(3.1$ \\
\hline 3 & 17.7 & 400 & $298(47)$ & 335 & $80(2.9)$ \\
\hline 4 & 16.8 & 370 & $311(31)$ & 355 & $80(4.1)$ \\
\hline 5 & 15.9 & 339 & $318(61)$ & 400 & $79.5(0.2)$ \\
\hline 6 & 15.0 & 308 & $319(3)$ & 520 & $77(3.8)$ \\
\hline 7 & 14.1 & 278 & $339(33)$ & 570 & $76(1.5)$ \\
\hline 8 & 13.2 & 254 & 330 (Ref.) & 580 & $71(2.1)$ \\
\hline 9 & 12.3 & 228 & $334(74)$ & 385 & $79(0.3)$ \\
\hline 10 & 11.4 & 202 & $299(44)$ & 600 & $76(1.4)$ \\
\hline 11 & 10.5 & 175 & Not measured & & \\
\hline 12 & 9.6 & 143 & $286(45)$ & 650 & $78(3.3)$ \\
\hline 13 & 8.7 & 113 & Not measured & & \\
\hline 14 & 7.8 & 83 & $259(0)$ & 500 & $75(1.4)$ \\
\hline 15 & 6.9 & 65 & Not measured & & \\
\hline 16 & 6.0 & 45 & $235(72)$ & 1200 & $68(1.1)$ \\
\hline
\end{tabular}

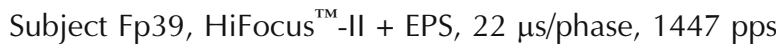

\begin{tabular}{|c|c|c|c|c|c|}
\hline \multirow[b]{2}{*}{ Electrode } & \multicolumn{2}{|c|}{ Insertion } & \multirow[b]{2}{*}{ Electric stimuli (C.U.) } & \multicolumn{2}{|c|}{ Acoustic stimuli } \\
\hline & Length (mm) & Angle $\left(^{\circ}\right)$ & & Frequency $(\mathrm{Hz})$ & Level (dB SPL) \\
\hline 1 & 16.7 & 517 & $381(22)$ & 260 & $78.5(2.8)$ \\
\hline 2 & 15.8 & 495 & Broken wire & & \\
\hline 3 & 14.9 & 454 & $384(23)$ & 320 & $81(2.7)$ \\
\hline 4 & 14.0 & 413 & $390(21)$ & 350 & $82(4.2)$ \\
\hline 5 & 13.1 & 370 & $412(15)$ & 400 & $84(0.3)$ \\
\hline 6 & 12.2 & 338 & $414(38)$ & 520 & $85.5(0.4)$ \\
\hline 7 to 16 & \multicolumn{5}{|c|}{ No contralateral hearing } \\
\hline
\end{tabular}


Subject H58, HiRes ${ }^{\mathrm{TM}} 90 \mathrm{~K}$ no EPS, $43 \mu \mathrm{s} /$ phase, 723 pps

\begin{tabular}{|c|c|c|c|c|c|}
\hline \multirow[b]{2}{*}{ Electrode } & \multicolumn{2}{|c|}{ Insertion } & \multirow[b]{2}{*}{ Electric stimuli (C.U.) } & \multicolumn{2}{|c|}{ Acoustic stimuli } \\
\hline & Length (mm) & Angle $\left(^{\circ}\right)$ & & Frequency $(\mathrm{Hz})$ & Level (dB SPL) \\
\hline 1 & 14.55 & 365 & $288(4)$ & 570 & $75(2.6)$ \\
\hline 2 & 13.7 & 330 & $440(25)$ & 680 & $76(3.3)$ \\
\hline 3 & 12.85 & 298 & $473(11)$ & 760 & $78(2.7)$ \\
\hline 4 & 12.0 & 267 & $459(36)$ & 800 & $76(1.5)$ \\
\hline 5 to 16 & \multicolumn{5}{|c|}{ No contralateral hearing } \\
\hline
\end{tabular}

Subject H68, HiRes ${ }^{\mathrm{TM}} 90 \mathrm{~K}$ no EPS, $22 \mu \mathrm{s} /$ phase, 1447 pps

\begin{tabular}{|c|c|c|c|c|c|}
\hline \multirow[b]{2}{*}{ Electrode } & \multicolumn{2}{|c|}{ Insertion } & \multirow[b]{2}{*}{ Electric stimuli (C.U.) } & \multicolumn{2}{|c|}{ Acoustic stimuli } \\
\hline & Length (mm) & Angle $\left(^{\circ}\right)$ & & Frequency $(\mathrm{Hz})$ & Level (dB SPL) \\
\hline 1 & 18.75 & 467 & Not measured & & \\
\hline 2 & 17.9 & 430 & $381(20)$ & 300 & $91(2)$ \\
\hline 3 & 17.05 & 390 & Not measured & & \\
\hline 4 & 16.2 & 351 & 397 (35) & 300 & $89(0.2)$ \\
\hline 5 & 15.35 & 307 & Not measured & & \\
\hline 6 & 14.5 & 274 & $423(21)$ & 350 & $85(2)$ \\
\hline 7 & 13.65 & 249 & 450 (Ref.) & Not measured & \\
\hline 8 & 12.8 & 225 & $473(37)$ & 500 & $82(3)$ \\
\hline 9 & 11.95 & 199 & Not measured & & \\
\hline 10 & 11.1 & 181 & $554(48)$ & 780 & $79(3.1)$ \\
\hline 11 & 10.25 & 162 & $561(69)$ & 900 & $78(0.1)$ \\
\hline 12 & 9.4 & 140 & Not measured & & \\
\hline 13 & 8.55 & 119 & $569(59)$ & 1600 & $73(3.3)$ \\
\hline 14 & 7.7 & 88 & Not measured & & \\
\hline 15 & 6.85 & 68 & Not measured & & \\
\hline 16 & 6 & 50 & Not measured & & \\
\hline
\end{tabular}

the pitch comparisons, following loudness balancing. For each subject, the type of the electrode array, the phase duration of the electric stimuli, and the rate of stimulation are indicated. Then each table lists the depth (in $\mathrm{mm}$ ) and angle (in ${ }^{\circ}$ ) of electrodes that were used in pitch comparisons, gives the electric amplitudes (in clinical units) producing a balanced loudness sensation on these electrodes, the frequency (in $\mathrm{Hz}$ ), as well as the level (in $\mathrm{dB} \mathrm{SPL}$ ) of the acoustic sine wave that roughly matched the pitch sensation produced by electrode stimulation. Numbers in parentheses describe the spread of the psychophysical curves (25-75\%) obtained for each loudness balancing measurement.

Measurements realized with subject Cp18 were conducted a few years before those conducted with the other patients. At that time, we simply asked the subject to adjust the stimuli for a "most comfortable" loudness sensation. We could not measure electrodes 11, 13, and 15 in subject Fp36 because she was not anymore available for testing.
Electrode 2 of subject Fp39 did not work, probably because of a broken wire. Pitch comparisons were not possible beyond electrode 6 for subject Fp39 because his contralateral residual hearing was limited to frequencies up to about $500 \mathrm{~Hz}$. Pitch comparisons were not possible beyond electrode 4 for subject H58 because his contralateral residual hearing was limited to frequencies up to about $1000 \mathrm{~Hz}$. We could not measure electrodes 1, 3, 5, 7, 9, 12, 14,15 , and 16 in subject $\mathrm{H} 68$ because he was not anymore available for testing.

\section{REFERENCES}

Bilger RC. Psychoacoustic evaluation of present prostheses. Ann. Otol. Rhinol. Laryngol. 86(Suppl. 38):92-140, 1977.

Blamey PJ, Dooley GJ, Parisi ES, Clark GM. Pitch comparisons of acoustically and electrically evoked auditory sensations. Hear. Res. 99:139-150, 1996. 
Boëx C, de Balthasar C, Kós M-I, Pelizzone M. Electrical field interactions in different cochlear implant systems. J. Acoust. Soc. Am. 114(4):2049-2057, 2003a.

Busby PA, Clark GM. Pitch and loudness estimation for single and multiple pulse per period electric pulse rates by cochlear implant patients. J. Acoust. Soc. Am. 101(3):1687-1695, 1997.

Busby PA, Whitford LA, Blamey PJ, Richardson LM, Clark GM. Pitch perception for different modes of stimulation using the cochlear multiple-electrode prosthesis. J. Acoust. Soc. Am. 95:2658-2669, 1994.

Clark GM, Shepherd RK, Franz BK-H, Dowell RC et al. The histopathology of the human temporal bone and auditory central nervous system following cochlear implantation in a patient. Correlation with psychophysics and speech perception results. Acta Oto-laryngol. (Stockh.). 448:1-65, 1988.

Cohen LT, Busby PA, Whitford LA, Clark GM. Cochlear implant place psychophysics. 1. Pitch estimation with deeply inserted electrodes. Audiol. Neuro-Otol. 1:265-277, 1996a.

Cohen LT, Xu J, Xu SA, Clark GM. Improved and simplified methods for specifying positions of the electrode bands of a cochlear implant array. Am. J. Otol. 17:859-865, 1996b.

Collins LM, TнRоскмовтоN CS. Investigating perceptual features of electrode stimulation via a multidimensional scaling paradigm. J. Acoust. Soc. Am. 108(5):2353-2365, 2000.

ColLins LM, Zwolan TA, WAKEFIELD GH. Comparison of electrode discrimination, pitch ranking, and pitch scaling data in postlingually deafened adult cochlear implant subjects. J. Acoust. Soc. Am. 101(1):440-455, 1997.

Dorman MF, Smith L, McCandless G, Dunnavant G, Parkin J, Dankowski K. Pitch scaling and speech understanding by patients who use the Ineraid cochlear implant. Ear Hear. 11:310-315, 1990

Dorman MF, Smith M, Smith L, Parkin JL. The pitch of electrically presented sinusoids. J. Acoust. Soc. Am. 95(3):1677-1679, 1994

EDDINGTON DK. Speech discrimination in deaf subjects with cochlear implants. J. Acoust. Soc. Am. 68:885-891, 1980.

Eddington DK, Dobelle WH, Brackmann DE, Mladejovsky MG, PARKIN JL. Place and periodicity pitch by stimulation of multiple scala tympani electrodes in deaf volunteers. Trans. Am. Soc. Artif. Intern. Organs XXIV:1-5, 1978a.

Eddington DK, Dobelle WH, Brackmann DE, Mladejovsky MG, PARKIN JL. Auditory prostheses research with multiple channel intracochlear stimulation in man. Ann. Otol. Rhinol. Laryngol. 87 (6, part 2, Suppl. 53):1-39, 1978b.

FAyAd JN, Luxford W, Linthicum FH. The Clarion electrode positioner: temporal bone studies. Am. J. Otol. 21:226-229, 2000.

Fayad J, Linthicium FH JR, Galey FR, Otto SR, House WF. Cochlear implants: histopathologic findings related to performance in 16 human temporal bones. Ann. Otol. Rhinol. Laryngol. 100:807-811, 1991.

Frinjs JHM, Briaire JJ, Grote JJ. The importance of human cochlear anatomy for the results of the modiolus-hugging multichannel cochlear implants. Otol. Neurotol. 22:340-349, 2001.

GALEY FR. Initial observations of a human temporal bone with a multi-channel implant. Acta Otol. (Stockh). 411(Suppl.):3844, 1984.

GREENWOOD DD. Critical bandwidth and frequency coordinates of the basilar membrane. J. Acoust. Soc. Am. 33:1344-1356, 1961.

GREENwOOD DD. A cochlear frequency-position function for several species-29 years later. J. Acoust. Soc. Am. 87(6):2592-2605, 1990.

James C, Blamey P, Shallop JK, Incerti PV, Nicholas AM. Contralateral masking in cochlear implant users with residual hearing in the non-implanted ear. Audiol. Neuro-otol. 6:87-97, 2001.
Johnson LG, House WF, Linthicium FH JR. Otopathological findings in a patient with bilateral cochlear implants. Ann. Otol. Rhinol. Laryngol., Suppl. 91 (2, Part 3):74-89, 1982.

Kawano A, Seldon HL, Clark GM. Computer-aided three-dimensional reconstruction in human cochlear maps: measurement of the lengths of organ of Corti, outer wall, inner wall and Rosenthal's canal. Ann. Otol. Rhinol. Laryngol. 105:701-709, 1996.

Kawano A, Seldon HL, Clark GM, Ramsden RT, Raine GH. Intracochlear factors contributing to psychophysical percepts following cochlear implantation. Acta Otolaryngol. (Stockh.). 118:313-326, 1998.

Kessler DK. The Clarion ${ }^{\circledR}$ Multi-Strategy ${ }^{\mathrm{TM}}$ cochlear implant. Ann. Otol. Rhinol. Laryngol. 108:8-16, 1999.

Kós M-I, Boēx C, Sigrist A, Guyot J-P, Pelizzone M. Measurements of electrode position inside the cochlea across different coch lear implant systems. Acta Oto-Laryngol. (Stockh.) 125:474480, 2005.

Liberman CM, Dodds LW, LEARson DA. Structure-function correlation in noise-damaged ears: a light and electron-microscopic study. In: Salvi RJ, Henderson D, Hamernick RP, Colletti V (eds) Basic and Applied Aspects of Noise-induced Hearing Loss. Plenum Press, New York, 1986.

Linthicum FH JR, Fayad J, Otto SR, Galey FR, House WF. Cochlear implant histopathology. Am. J. Otol. 12(4):245-311, 1991.

Marsh MA, Coker NJ, Jenkins HA. Temporal bone histopathology of a patient with a Nucleus 22-channel cochlear implant. Am. J. Otol. 13(3):241-248, 1992.

Marsh MA, Xu J, Blamey PJ, Whitford LA, Xu SA, Silverman JM, CLARK GM. Radiologic evaluation of multichannel intracochlear implant insertion depth. Am. J. Otol. 14(4):386-391, 1993.

McKay CM, McDermott HJ, Clark GM. The perceptual dimensions of single-electrode and nonsimultaneous dual-electrode stimuli in cochlear implantees. J. Acoust. Soc. Am. 99:1079-1090, 1996.

Nadol JB JR, Ketten DR, Burgess BJ. Otopathology in a case of multichannel cochlear implantation. Laryngoscope 104:299303, 1994

Nadol JB Jr, Shia Jy, Burgess BJ, Ketten DR, Eddington DK, Gantz BJ, Kos I, Montandon P, Coker NJ, Roland JT, Shallop JK. Histopathology of cochlear implants in the human. Ann. Otol. Rhinol. Laryngol. 110(9):883-891, 2001.

Nelson DA, Van Tasell DJ, Schroder AC, Soli S, Levine S. Electrode ranking of "place pitch" and speech recognition in electrical hearing. J. Acoust. Soc. Am. 98(4):1987-1999, 1995.

O'Leary MJ, House WF, Fayad J, Linthicium FH Jr. Electrode insertion trauma in cochlear implantation. Ann. Otol. Rhinol. Laryngol. 100:695-699, 1991.

Pelizzone M, Boëx C, Montandon P. Vowel and consonant identification tests can be used to compare performances in a multilingual group of cochlear implant patients. ORL 55:341346, 1993

Sellick PM, Patuzzi R, Johnston BM. Measurement of basilar membrane motion in the guinea pig using the Mossbauer technique. J. Acoust. Soc. Am. 33:1381-1385, 1982.

SHANNON RV. Multichannel electrical stimulation of the auditory nerve in man. I. Basic psychophysics. Hear. Res. 11:157-189, 1983.

Shannon RV. Psychophysics. In: Tyler RS (eds) Cochlear Implants: Audiological Foundations. Singular Publishing Inc., San Diego, 1993.

Simmons FB, Mathews RW, Walker MG, White RL. A functional multichannel auditory nerve stimulator. Acta Otolaryngol. 87:170-175, 1979.

Sridhar D, Stakhovskaya O, Leake PA. A frequency-position function for the human spiral ganglion. Assoc. Res. Otolaryngol. Abs. 28(909):318, 2005.

Terr LI, Sfogliano GA, Riley SL Jr. Effects of stimulation by cochlear implant of the cochlear nerve. Laryngoscope 99:1171-1174, 1989. 
Tong YC, Blamey PJ, Dowell RC, Clark M. Psychophysical studies evaluating the feasibility of a speech processing strategy for a multiple-channel implant. J. Acoust. Soc. Am. 74:73-80, 1983.

Tong YC, CLARK M. Absolute identification of electric pulse rates and electrode positions by cochlear implant patients. J. Acoust. Soc. Am. 77(5):1881-1888, 1985.

Townshend B, Cotter N, Van Compernolle D, White RL. Pitch perception by cochlear implant subjects. J. Acoust. Soc. Am. 82:106-115, 1987.

Verbist BM, Frijns JHM, Geleijns J, van Buchem MA. Multisection CT as a valuable tool in the postoperative assessment of cochlear implant patients. AJNR Am. J. Neuroradiol. 26(2): 424-429, 2005.

vON BÉKÉSY G. Experiments in Hearing. McGraw-Hill, New York, 1960

Xu J, Xu SA, Cohen LT, Clark GM. Cochlear view: postoperative radiography for cochlear implantation. Am. J. Otol. 21:49-56, 2000.

Zappia JJ, Niparko JK, Kemink JL, Oviatt DL, Altschuler RA. Evaluation of the temporal bones of a multichannel cochlear implant patient. Ann. Otol. Rhinol. Laryngol. 100:914-921, 1991.

Zwislokci JJ, NGUYen M. Place code for pitch: a necessary revision. Acta Otolaryngol. 19:140-145, 1999. 